\title{
LETTER
}

\section{Trained innate immunity as a mechanistic link between sepsis and atherosclerosis}

\author{
Siroon Bekkering, Leo AB Joosten, Mihai G Netea and Niels P Riksen ${ }^{*}$ \\ See related research by Kaynar et al., http://ccforum.com/content/18/5/469
}

Cardiovascular events have been associated with previous infections in many observational studies. In the previous issue of Critical Care, Kaynar and colleagues [1] corroborated this association by showing in atherosclerosis-prone mice that the cecal-ligation-and-puncture (CLP) model of sepsis accelerates aortic atherosclerotic plaque formation up to 5 months after CLP. In addition, the authors observed higher circulating interleukin- 6 and -10 levels and a greater infiltration of macrophages in the aortic root at 5 months after CLP. Although these findings substantiate the association between infection and atherosclerosis, the underlying mechanism of the persistent inflammation remains enigmatic.

We propose the newly described process of trained immunity as the mechanistic link between previous infection and atherosclerosis. Trained immunity denotes the nonspecific immunological memory that can be activated in monocytes [2,3]. Brief exposure of monocytes to microbial products (including Candida albicans or its cell wall component beta-glucan) induces a long-lasting proinflammatory macrophage phenotype via epigenetic reprogramming mediated by histone modifications $[2,3]$. Further analyses revealed global pan-activation of these macrophages rather than simple skewing into M1 or M2 subtypes [3].

Given the pivotal role for monocytes/macrophages in atherosclerotic plaque development, we recently hypothesized that trained innate immunity contributes to atherosclerosis [4]. Indeed, epigenetic reprogramming of monocytes induced a long-lasting pro-atherosclerotic phenotype, characterized by increased cytokine and chemokine release and increased foam cell formation [5].

Considering these findings, we propose that epigenetic reprogramming of monocytes after CLP explains the persistent inflammation and accelerated atherosclerosis. Since epigenetic reprogramming is amenable to pharmacological modulation, further elucidation of this mechanism might provide novel treatment strategies for atherosclerosis [5].

\section{Authors' response}

A Murat Kaynar, Alyssa D Gregory, Steven D Shapiro and Derek C Angus

We read the letter by Bekkering and colleagues with interest. We completely agree that the mechanism behind the sustained inflammation 5 months after recovery from sepsis remains enigmatic. The goal of our article [1] was to overcome the shortcomings of prior human observational studies by constructing an experiment model in which we could make causal inference. However, although we have helped establish a causal relationship, we do not know 'how' it actually happens. We concur that there could be innate 'training' through epigenetic changes leading to augmented inflammatory response by monocytes/macrophages in the absence of ongoing infection. As reported by the group, the concept of 'learned innate immunity' brings the innate immunity to the limelight [2]. However, the decision tree when the innate immunity does switch from a 'tolerant' to an energetically costly 'learned' state is not clear $[1,6,7]$.

To conclude, we also think that 'learned immunity' could play a role in our observations. However, is 'learned immunity' really of benefit to the organism? If not, why do we still carry that burden?

\footnotetext{
* Correspondence: niels.riksen@radboudumc.nl

Department of Internal Medicine, Division of Vascular Medicine and

Experimental Internal Medicine, Radboud University Medical Center, Geert

Grooteplein 10, Nijmegen 6525 GA, The Netherlands
} 


\section{Abbreviation}

CLP: Cecal-ligation-and-puncture.

\section{Competing interests}

The authors declare that they have no competing interests.

Published online: 25 November 2014

\section{References}

1. Kaynar AM, Yende S, Zhu L, Frederick DR, Chambers R, Burton CL, Carter M, Stolz DB, Agostini B, Gregory AD, Nagarajan S, Shapiro SD, Angus DC: Effects of intra-abdominal sepsis on atherosclerosis in mice. Crit Care 2014, 18:469.

2. Cheng SC, Quintin J, Cramer RA, Shepardson KM, Saeed S, Kumar V, Giamarellos-Bourboulis EJ, Martens JHA, Rao NA, Aghajanirefah A, Manjeri GR, Li Y, Ifrim DC, Arts RJ, van der Meer BM, Deen PM, Logie C, O'Neill LA, Willems P, van de Veerdonk FL, van der Meer JW, Ng A, Joosten LA, Wijmenga C, Stunnenberg HG, Xavier RJ, Netea MG: mTOR- and HIF-1a-mediated aerobic glycolysis as metabolic basis for trained immunity. Science 2014, 345:1250684.

3. Quintin J, Saeed S, Martens JH, Giamarellos-Bourboulis EJ, Ifrim DC, Logie C, Jacobs L, Jansen T, Kullberg BJ, Wijmenga C, Joosten LA, Xavier RJ, van der Meer JW, Stunnenberg HG, Netea MG: Candida albicans infection affords protection against reinfection via functional reprogramming of monocytes. Cell Host Microbe 2012, 12:223-232.

4. Bekkering S, Joosten LA, van der Meer JW, Netea MG, Riksen NP: Trained innate immunity and atherosclerosis. Curr Opin Lipidol 2013, 24:487-492.

5. Bekkering S, Quintin J, Joosten LA, van der Meer JW, Netea MG, Riksen NP: Oxidized low-density lipoprotein induces long-term proinflammatory cytokine production and foam cell formation via epigenetic reprogramming of monocytes. Arterioscler Thromb Vasc Biol 2014, 34:1731-1738.

6. Maitra U, Deng H, Glaros T, Baker B, Capelluto DG, Li Z, Li L: Molecular mechanisms responsible for the selective and low-grade induction of proinflammatory mediators in murine macrophages by lipopolysaccharide. J Immunol 2012, 189:1014-1023.

7. Medzhitov R, Schneider DS, Soares MP: Disease tolerance as a defense strategy. Science 2012, 335:936-941.

doi:10.1186/s13054-014-0645-3

Cite this article as: Bekkering et al:: Trained innate immunity as a mechanistic link between sepsis and atherosclerosis. Critical Care 2014 18:645. 